\title{
Nuevo malestar en la cultura: El «des-alejamiento» del alejamiento o la conquista del espacio exterior
}

\author{
New uneasiness in culture: \\ The «de-distancing» of distancing or \\ the conquest of outer space
}

\author{
BORJA GARCÍA FERRER \\ Departamento de Filosofía II, Universidad de Granada
}

Recibido: 28/10/2012 Aceptado: 22/11/2012

\begin{abstract}
RESUMEN
El objetivo del presente trabajo es examinar, desde un enfoque epistemológico interdisciplinar, la vigencia o la actualidad que posee la visión heideggeriana de la decadencia occidental en la infoesfera, en virtud de la superación virtual del espacio-tiempo que conllevan, a mediados del Novecientos, las nuevas tecnologías de la información y la comunicación (NTIC). Como trataré de mostrar, el fenómeno óntico de la comunicación instantánea no hace sino consolidar y poner de manifiesto en la praxis histórico-vital el «máximo olvido del ser» que Heidegger teoriza a nivel ontológico.

PALABRAS CLAVE
HEIDEGGER, TÉCNICA MODERNA, «MÁXIMO OLVIDO DEL SER»,
COMUNICACIÓN INSTANTÁNEA, SUPERACIÓN VIRTUAL DEL ESPACIO-TIEMPO
\end{abstract}

\section{ABSTRACT}

The aim of the current work is to study, from an interdisciplinary epistemological approach, the relevance or validity of the Heideggerian view on the western decadence in the infosphere, by means of the virtual superseding of space-time brought by the new information and communi-

(C) Contrastes. Revista Internacional de Filosofia, vol. XIX-Nº1 (2014), pp. 65-82. ISSN: 1136-4076

Departamento de Filosofía, Universidad de Málaga, Facultad de Filosofía y Letras Campus de Teatinos, E-29071 Málaga (España) 
cation technologies (NICT) in the mid $20^{\text {th }}$ century. As I will try to show, the ontic phenomenon of instant communication does nothing but highlight and strengthen in the historical and vital praxis the «fullest forgetfulness of being» theorized by Heidegger on an ontological level.

KEY WORDS

HEIDEGGER, MODERN TECHNOLOGY, «FULLEST FORGETFULNESS OF BEING», INSTANT COMMUNICATION, VIRTUAL SUPERSEDING OF SPACE-TIME

\section{INTRODUCCIÓN: DECLARACIÓN DE INTENCIONES Y CIRCUNSTANCIAS}

Como ReZa el tóPICo político, nos encontramos en tiempos de crisis. Pero por mucho que los técnicos del poder alimenten las habladurías tendentes a reducir el peligro que atraviesa el corazón de nuestro presente a la mera dimensión economicista, el nuevo malestar en la cultura que todos experimentamos diariamente perturba en primera instancia, como lo invisible de lo visible, el suelo profundo del espacio socio-cultural. En este sentido, la función crítica que viene acompañando a nuestra insigne disciplina desde siempre ha desempeñado, a lo largo del siglo XX, un esfuerzo titánico con vistas a dilucidar las señas de identidad del desfallecimiento que padece el espíritu occidental, en lo que concierne a su comprensión del mundo y sus proyectos o metas vitales.

Sobre los hombros de gigantes como Nietzsche, la Escuela de Frankfurt, Heidegger o la filosofía de la diferencia, el pensamiento ha sabido mantenerse a la altura del acontecimiento, no sólo en relación a las fuerzas ciegas que aumentan exponencialmente el malestar generalizado a la espalda de nuestras conciencias, sino que también ha posado la mirada atenta sobre sus facciones morbosas de superficie, abriendo un horizonte sapiencial que inscribe la promesa epistemológica de un enfoque interdisciplinar por-venir, donde la mirada holística de la filosofía, que se retira anacoréticamente de los hechos positivos para captar la raíz ontológica del problema en su estado naciente, y el valor cognoscitivo de las ciencias humanas y sociales, con la audacia suficiente para medir el grado de intensidad de las enfermedades efectivas y perceptibles, conjuguen sus potencialidades, contra el monopolio de la hiperespecialización científica que nos azota (sobre todo, a partir del siglo XIX, aunque se remonta hasta el Renacimiento), generando una especie de esquizofrenia entre el hombre y la naturaleza, de un lado, y frente al fenómeno de la «investigación convertida en empresa», como lo denomina el propio Heidegger, de otro.

En este contexto teórico, el trabajo que nos ocupa se alinea en las filas heideggerianas para explotar el potencial descriptivo e interpretativo del arsenal conceptual que utiliza para analizar la decadencia occidental, entendida como «máximo olvido del ser», a fin de comprobar el recorrido que posee en el ámbito concreto del sistema global de información y comunicación. Se trata, desde esta perspectiva, de mostrar las consecuencias mórbidas de la transformación 
que han experimentado las relaciones entre lo cercano y lo lejano a partir del establecimiento de la co-instantaneidad entre acontecimiento y noticia por parte de las incipientes tecnologías telemáticas, con el afán de complementar ónticamente la pureza ontológica que caracteriza a la imagen científico-técnica del mundo proyectada por Heidegger.

De este modo, pretendemos poner de manifiesto, por una parte, la trascendencia que posee una filosofía tan especulativa como la heideggeriana en la praxis comunicativa, una tarea vital de cara a que la disciplina filosófica pueda tener verdaderos encuentros más allá del cálido reducto académico, si tomamos en consideración el carácter enigmático del lenguaje heideggeriano. Por otra parte, aspiramos a esclarecer, por mor de los presupuestos ontológicos de nuestro filósofo, el devenir enfermizo del hecho tecnológico en la infoesfera, cuya vertiginosa celeridad lo ha mantenido oculto, hasta el momento, a la hora de hacerle justicia (a pesar de la copiosa literatura que ha generado). Se trata, no obstante, de una exigencia inexcusable para el pensamiento crítico, ante el carácter primordial que poseen las tecnologías de la información y la comunicación en nuestro estilo de vida, hasta el punto de que constituyen verdaderas extensions of man.

Para llevar a buen puerto tales propósitos, vamos a comenzar contraponiendo la concepción heideggeriana de la técnica originaria a la de la técnica moderna en cuanto esencia de nuestra época y, por ende, germen de la decadencia occidental. Con el objeto de lograr una síntesis coherente a este respecto, trataré de complementar mis propias lecturas con algunas líneas hermenéuticas de la filosofía de Heidegger, en un sentido netamente expositivo que es conditio sine qua non, a modo de plataforma o lanzadera, para entender adecuadamente el desarrollo ulterior del asunto, puesto que el malestar preponderante constituye, tal y como lo entiende el filósofo alemán, los cimientos que sustentan nuestra crítica de patologías.

Una vez entendido, en función de la concepción heideggeriana de lo real, en qué sentido es decadente la técnica moderna, analizaremos desde la óptica de la «diferencia óntico-ontológica» las repercusiones escabrosas que se siguen del triunfo de la instalación manipulable del mundo en el caso de su «des-alejamiento» por obra y gracia de la comunicación instantánea; para ello, confrontaré el planteamiento de Heidegger con la tradición post-heideggeriana e, incluso, con corrientes de pensamiento más próximas a las ciencias antroposociales que a la filosofía propiamente dicha, si se nos permite hablar en términos disciplinares toda vez que el plano ontológico y el plano óntico constituyen dos rostros del acontecimiento. 


\section{Nivel ONTOLÓGICO: El FONDO PATOLÓGICO DE LA TÉCNICA MODERNA}

Desde los tiempos en que el pensamiento occidental apenas daba sus primeros pasos, ${ }^{1}$ la versión humanística de la técnica, dominante en la reflexión antropológica, ha venido considerando bajo semblantes de lo más variopinto que la esencia de la técnica (aquello que es) consiste en un «hacer» del hombre, un hacer entendido como «medio» (to metaxy) para unos fines. En este sentido, la técnica garantiza la liberación del reino de la necesidad ${ }^{2}$ y contribuye a que el hombre alcance, en cuanto animal instrumentificum o animal tools making, la integridad cultural y espiritual de su ser, de tal manera que constituye la condición de posibilidad de la vida humana, un paradigma de existencia, un lema de la humanidad.

Ciertamente, la concepción instrumental de la técnica es correcta en el sentido de que constata lo que hay ante-los-ojos, del mismo modo que también lo es para la técnica moderna, tal y como atestiguan las centrales hidroeléctricas o la industrias mineras y petrolíferas. Pero a pesar de ser correcta, dicha definición no es esencial, o sea, no desvela la esencia de lo que está-ahí-delante, su ser más profundo o su verdad: «La técnica no es lo mismo que la esencia de la técnica. Cuando buscamos la esencia del árbol, tenemos que darnos cuenta de que aquello que prevalece en todo árbol como árbol no es a su vez un árbol que se pueda encontrar entre los árboles». ${ }^{3}$ De aquí la célebre «diferencia óntico-ontológica» heideggeriana entre el ser de los entes (lo que los patentiza abriéndolos a la presencia) y los mismos entes, en lo que constituye un presupuesto inevitable del pensar, a saber, «que lo ente y el ser siempre sean descubiertos a partir de la diferencia y en ella». ${ }^{4}$

Desde este punto de vista, el filósofo alemán nos invita a realizar un abordaje de la técnica en clave metafísica, con el objeto de esclarecer su radical alcance ontológico o, lo que es lo mismo, su sentido originario. Para ello, pro-

1 Nos referimos concretamente al mito de Prometeo, quien en el fuego robado a los dioses otorgó al hombre, según Esquilo, tanto la habilidad técnica como la confianza en ella, y la posterior identificación de lo humano con la empresa de Prometeo a cargo de Sófocles. $C f$. P. Cerezo Galán, «Metafísica, técnica y humanismo en Martin Heidegger», Taula. Quaderns de Pensament, 13-14 (1990), pp. 31-32.

2 Desde luego, la posición de Ortega constituye un clásico ineludible al respecto: «La técnica es [...] la reforma que el hombre impone a la naturaleza en vista de la satisfacción de sus necesidades. [...] Reforma en sentido tal que las necesidades quedan, a ser posible, anuladas [...] en cuanto [...] menesterosidad, negación, problema y angustia». J. Ortega y Gasset, Meditación de la técnica. Madrid: Espasa-Calpe, 1965, pp. 21-22.

3 M. Heidegger, «La pregunta por la técnica», en Conferencias y artículos, tr. E. Barjau. Barcelona: Serbal, 1994, p. 9.

4 M. Heidegger, «La constitución onto-teo-lógica de la metafísica», en Identidad y diferencia, tr. H. Cortés y A. Leyte. Barcelona: Anthropos, 1988, p. 137. 
cede problematizando lo correcto, o sea, lo instrumental en cuanto tal. Si bien es cierto que una de las principales aportaciones de Aristóteles a la historia de las ideas ha sido asimilar lo instrumental a la cuádruple causalidad (material, formal, final y eficiente), el significado propio de la noción de «causa» (su carácter unitario) pasó desapercibido para el Estagirita.

A este respecto, nuestro filósofo aclara que la esencia de la causalidad consiste en «aquello que es responsable de algo», de tal manera que las cuatro causas no son sino cuatro modos del ser responsable que se pertenecen mutuamente. No hay que entender este ser responsable, en cualquier caso, desde una óptica moral o como un modo del efectuar, sino en el sentido de un «ocasionar»: los cuatro modos del ser responsable dejan venir a algo todavía no presente al aparecer, lo traen-ahí-delante, lo pro-ducen poiéticamente. Ahora bien, dicho venir a presencia sólo tiene propiamente lugar cuando consiste en un «salir de lo oculto» (Entbergen) o «des-ocultamiento» (alétheia ${ }^{5}$ ) que muestra algo a la luz de su esencia, ${ }^{6}$ de modo que lo posibilita en su verdad, con lo cual asistimos a una interpretación aletológica de la poiesis.

Llegados a este punto, estamos en condiciones de vislumbrar la esencia de la técnica y recoger así los frutos de nuestra paciente reflexión en torno a lo instrumental en cuanto tal: la técnica es un «modo del salir de lo oculto que pone en obra el ser de las cosas», en función de lo cual pertenece a la región de la verdad; por consiguiente, es más originaria que una mera disposición instrumental humana, contra la definición tradicional de la técnica.

En realidad, la técnica sólo remite al hombre de manera indirecta, entendido como «lugar abierto ( $(D a-$-sein»), como una herida o una brecha, por donde irrumpe lo otro de sí»; ${ }^{7}$ de aquí se sigue que lo que sea el hombre debe considerarse en relación a lo que no es él, ${ }^{8}$ esto es, el protofenómeno

5 Como buen antimetafísico, Heidegger se remonta a los presocráticos (Heráclito, en especial) para oponer la noción de verdad como «alétheia» (los entes en el «cómo»o «en cuanto» de su estado de descubiertos) al concepto de verdad como «adaequatio» del juicio con su objeto que encontramos en la práctica totalidad de la tradición metafísica onto-teo-lógica. $C f$. M. Heidegger, El Ser y el Tiempo, tr. J. Gaos. Madrid: FCE, 1989, pp. 233-52.

6 Lo alumbra en los dos sentidos que comprende el término español, a saber: «dar a luz» y «mantener a la luz». $C f$. P. Cerezo, Loc. cit., p. 34.

7 Ibid. p. 33.

8 La ontología heideggeriana es fundamental, dado que contiene una antropología sin reducirse a ella, o sea, el ser incluye el sentido del hombre, pero ambos no se equiparan. En esta medida, el pensador de Friburgo termina de una vez por todas, más allá del a priori de correlación o unidad sintética entre experiencia y realidad de su maestro Husserl, con la antropomorfización del ser que se funda en la supremacía autosuficiente del cogito y el carácter primordial de la actitud teorética-reflexiva, la cual aspira a re-presentarlo especulativa y violentamente: «La 'conciencia de la realidad' es ella misma un modo del 'ser en el mundo'. [...] La primera proposición sería entonces: 'sum', y en este sentido: 'yo soy en un mundo'. En cuanto ente tal, 
fundante que le fuerza y arroja (Geworfen) constantemente a ex-ponerse en la facticidad, haciendo las veces de nervadura para cualquier ser-de-un-modo: «Dondequiera que el hombre abra sus ojos y sus oídos, allí donde franquee su corazón o se entregue libremente a meditar y aspirar, a formar y obrar, a pedir y agradecer, se encontrará en todas partes con que se le ha llevado ya a lo desocultado». ${ }^{9}$ Solamente en la medida en que pertenece al «misterio» de violencia del des-velamiento (Enthülltheit) de la verdad ontológica, el hombre, en cuanto «ex-sistencia» $\left(\right.$ Ek-sisten $\left.{ }^{10}\right)$, «claro» o «apertura» a la verdad del ser, es lo más inquietante.

Por su parte, la técnica moderna se define como el «hacer salir lo oculto» que nos constituye en la actualidad, y supone una transformación cualitativa de la función poiética, así como una inversión decisiva de los papeles asumidos tradicionalmente por physis ${ }^{11}$ y técnica. Como todo pro-ducir poiético, la técnica se inserta en el ámbito ontológico de la physis, de manera tal que su función originaria consiste en un «cuidar con solicitud» (Bestellen) que tenga cumplimiento su dinamismo interno. En el caso de la técnica moderna, sin embargo, esta actitud respetuosa se torna en una construcción espantosa, «una provocación que pone ante la Naturaleza la exigencia de suministrar energía que como tal pueda ser extraída y almacenada»;12 de este modo, «la naturaleza

'soy' en la 'posibilidad de ser relativamente a diversas actividades (cogitationes) como modos del ser cabe los entes intramundanos'. Descartes, en cambio, dice: las cogitationes son 'ante los ojos' y en ellas es un ego también 'ante los ojos' como res cogitans sin mundo». M. Heidegger, El Ser y el Tiempo, op. cit., pp. 231-32. En efecto, cuando reflexionamos sobre nuestras propias vidas, «primero se encuentra la prisión y luego, dentro de ella, el prisionero». J. Ortega, Unas lecciones de metafisica. Madrid: Alianza, 1970, p. 80.

9 M. Heidegger, «La pregunta por la técnica», Loc. cit., p. 21. Si bien es cierto que semejante presupuesto ontológico no adquiere toda su radicalidad hasta la Kehre, Heidegger se desmarca ya desde Ser y Tiempo del afán sustancialista que caracteriza a la «metafísica de la presencia» a la hora de comprender al hombre: «La 'esencia' del 'ser ahi' está en su existencia. [...] El 'ser ahí' es mío en cada caso, a su vez, en uno u otro modo de ser. Se ha decidido ya siempre de alguna manera en qué modo es el 'ser-ahí' mío en cada caso». [...] «El 'estado de descubiertos' de los entes intramundanos se funda en el 'estado de abierto' del mundo. [...] El 'ser ahí' es en la verdad». M. Heidegger, El Ser y el Tiempo, Op. cit., p. 54; pp. 241-42.

10 Nótese que esta noción se distancia, tanto desde el punto de vista de la forma como del contenido, del concepto tradicional de «existencia» (existentia) como «realidad efectiva» de lo real, en oposición a la «esencia» (essentia), que significa «posibilidad». $C f$. M. Heidegger, «Carta sobre el 'humanismo'», en Hitos, tr. H. Cortés y A. Leyte. Madrid: Alianza, 2000, pp. 268-69.

11 Heidegger entiende por physis el «sustrato natural» de la historia que impera sobre todas las cosas, «sede hospitalaria», «horizonte unitario»y «fuente de creación» que posibilita todo cuanto es. $C f$. D. Sánchez Meca, «Heidegger: la 'imposición' universal de la técnica y la nueva relación del hombre con el ser», en El nihilismo. Perspectivas sobre la historia espiritual de Europa. Madrid: Síntesis, 2004, pp. 174-78.

12 M. Heidegger, «La pregunta por la técnica», Loc. cit., p. 17. 
se convierte [...] en una única estación gigantesca de gasolina, en fuente de energía para la técnica y la industria modernas». ${ }^{13}$

En efecto, la técnica moderna es una forma del acaecer de la verdad, una destinación del sino que somete y desafía a la naturaleza a que preste un rendimiento prescrito por un plan determinado, en lo que constituye la clave metafísica o el núcleo ontológico de nuestra época, esto es, la relación ontológica «demandante/dispuesto» que Heidegger denomina «Ge-stell» («estructura de emplazamiento», «armazón»). Este pavoroso «emplazar que provoca» (Herausforderndes Stellen) a la naturaleza posee el carácter de un promover orientado, según el método científico de Galileo, hacia la máxima eficiencia, ${ }^{14}$ en aras de una dirección y un aseguramiento avalados pragmáticamente por un lujoso sistema de modi operandi, regulaciones y ajustes concretos $;{ }^{15}$ en este sentido, la técnica moderna consiste, como la antigua physis, en un poder directivo y autónomo, hasta el punto de que encierra en sí, en cuanto a priori ontológico, la posibilidad de toda realidad.

Heidegger denomina «existencia» o «fondo» (Bestand), en un sentido propiamente bancario y monetario, al estado de desocultamiento (Offenbarkeit) propio del emplazar desafiante, es decir, el modo como se halla presente. Las «existencias» efectivas, cuantificables por medio del cómputo y acumulables

13 M. Heidegger, Serenidad, tr. Y. Zimmermann. Barcelona: Serbal, 1989, p. 23.

14 El significado del término «eficiencia» se entiende aquí en un sentido horizontal, según el cual el operar de la acción es reductible a «cantidad», en contraste con el sentido vertical de su origen latino (efficacitas), que significa «poder para obrar», donde la acción es irreductible a sus producciones externas. $C f$. L. Sáez Rueda, «Ficcionalización del mundo. Aportaciones para una crítica de patologías sociales», Revista de Filosofia Universidad de Costa Rica, 115-116 (2007), pp. 60-61.

15 Según Heidegger, el nihilismo tecnológico que nos hospeda entre sus eternos brazos traduce los postulados teóricos de la tradición metafísica en la estructura material de lo efectivamente real, de tal manera que, del mismo modo que existe una esencia metafísica de la técnica, cabe hablar de una esencia técnica de la metafísica. El cortejo triunfal de la técnica consumada constituye, de hecho, la ejecución definitiva de un proceso histórico de creciente decadencia gestado por la fatídica identificación del ser con el hipokéimenon («lo que siempre preyace»), esto es, la nihilización de la physis a cargo del pensamiento griego: «La filosofía griega [...] se atuvo al primer plano de lo que está presente (Anwesenheit) en sí mismo. [...] El originario y emergente erguirse del poderío de lo que impera [...], entendido en gran sentido, como el aparecer, como la epifanía de un mundo, se convierte en visibilidad mostrable. [...] Es natural que el ente siga siendo. Su mezcla se da con más ruido y con más amplitud que nunca; pero el ser se ha retirado de él. [...] Entonces se ha iniciado la decadencia». M. Heidegger, Introducción a la Metafísica, tr. E. Estiú. Buenos Aires: Nova, 1980, pp. 99-100. En este sentido, el filósofo participa de la estampa antigua de la historia como una senda destinal de nihilismo, degeneración y caída a partir de un pasado esplendoroso, con lo que cobra vigencia el refrán popular que reza: «Cualquier tiempo pasado fue mejor». 
como un sistema de informaciones, se caracterizan básicamente por encontrarse a la «disposición» del hombre como las mercancías en el mercado, de tal manera que la consistencia de lo real queda desintegrada por completo en la dimensión instrumental de la presencia manipulable, más allá de la comprensión moderna del ser del ente como objeto (Gegenstand) de la representación humana. Ahora bien, ¿qué entiende Heidegger exactamente por «realidad»?

Para hacernos una idea cabal al respecto, es de recibo comparar heurísticamente su concepción de la historia con la de Hegel. Mientras que éste postula una teleología escatológica donde el despliegue de lo absoluto entreteje los distintos estadios de la verdad a partir de un origen que se conserva hasta una realización culminante y suprema, Heidegger subraya la finitud de la historia, desde su comienzo en la relación ontológica del hombre con lo que es hasta su final en la época de la técnica. Desde este prisma, advierte que existen dimensiones del ser que no son históricas y, de este modo, rompe con la identificación hegeliana entre ser e historia, dando lugar a una eventualización del sentido según la cual el ser no es sino que acontece, esto es, trae a presencia un mundo $\mathrm{u}$ horizonte de sentido de manera tal que ilumina con su des-velamiento una época, otorgándole una unidad, un modo de ser e, incluso, unas verdades compartidas. Sin embargo, las posibilidades propias de una era no incluyen muchas otras, pues el advenimiento del ser en cada época es también, necesariamente, un ocultarse que favorece el olvido de todas las posibilidades de existencia que no ven la luz. De aquí la radical finitud de todas las épocas y, por ende, el despropósito hegeliano de un supuesto desvelamiento total del ser.

Así las cosas, el de Friburgo define el ser como acontecimiento unitario de «des-cubrimiento/encubrimiento» (Ereignis), en lo que constituye un presupuesto ontológico ineludible para entender su pensamiento, a saber, la co-pertenencia o simultaneidad entre el ser y la nada. ${ }^{16}$ Ahora bien, en la medida en que se retira, el ser se hurta a nuestra mirada ${ }^{17} \mathrm{y}$, por lo tanto, es irrepresentable (so pena de entificarlo), sólo puede ser-aprehendido experiencial y páticamente ${ }^{18}$. Para encontrarnos genuinamente con el mundo, es necesario

16 Esta noción de «nada» no tiene nada que ver con el concepto al uso de «nada» como «lo absolutamente no-ente» que la ciencia utiliza, porque es más originaria que el «no» y la «negación»y, por lo tanto, no puede ser considerada desde el punto de vista formal de la lógica universal. $C f$. M. Heidegger, «¿Qué es metafísica?», en Hitos, op. cit., pp. 96-97.

17 «Imaginemos un mundo sin espejos. En él cada ojo permite ver, pero no puede verse a sí mismo. En el seno de la facticidad ésta abre la claridad desde la que comprendemos. [...] Ahora bien, ella misma, permitiendo una dirección de la mirada, no puede ser aprehendida». L. Sáez, Ser errático. Una ontología crítica de la sociedad. Madrid: Trotta, 2009, p. 67.

18 Podríamos decir, empleando la archiconocida fórmula de L. Wittgenstein, que el ser «no puede ser dicho sino que sólo puede ser mostrado», en virtud de lo cual el lenguaje conceptual no es sino «una escalera que hay que tirar tras haberla subido», como diría el propio filósofo. 
adoptar libremente una disposición pastoril para que lo dado en la experiencia nos interpele, es decir, la pasividad activa o actividad pasiva propia de la escucha que se supedita, dejar-ser-al-ser con tal de posibilitar su apertura de sentido: «La textura ontológica de lo real se hace accesible a condición de dejar aparecer las 'cosas mismas' en su autodonación». ${ }^{19}$

\section{Nivel ÓNTICO: El ALCANCE PATOLÓGICO DE LA TÉCNICA MODERNA}

Es bien conocido el pasaje de Ser y Tiempo donde Heidegger advierte que el «Da-sein» es originariamente espacial en el modo de la «des-alejación», es decir, busca naturalmente, a través de los sentidos de la vista y el oído, superar la lejanía de lo que está alejado o, si se quiere, posee una tendencia esencial a trascender el horizonte local de los acontecimientos. Pues bien, esta propensión consustancialmente protésica late en el seno de las flamantes tecnologías de la «tele-presencia», cuyas estrategias procedimentales irrumpen donde el apéndice natural se torna insuficiente para mediatizar lo real, a modo de prolongación imaginaria de la lógica vital que vertebra nuestros esquemas somáticos; el mismo Heidegger suscribe en esta dirección que «todas las formas de aumento de la velocidad a las que hoy cedemos más o menos forzosamente, impulsan a superar la lejanía. Con la 'radio', por ejemplo, lleva hoy a cabo el 'ser-ahí', por el camino de una ampliación del cotidiano mundo circundante, un desalejamiento del 'mundo'». ${ }^{20}$

El nuevo paradigma informacionalista instaura, efectivamente, la comunicación instantánea a nivel planetario, modificando profundamente la estructuración metafísica que ha articulado las relaciones milenarias entre lo próximo y lo distante, así como las jerarquías y los valores que han cimentado la coherencia interna de la existencia en los diversos episodios de la historia del ser. Aunque la memoria histórica no constituya, precisamente, el leitmotiv de nuestro tiempo, es bien sabido que, antes del allanamiento de la cultura protagonizado por las nuevas tecnologías de la comunicación, debía transcurrir un tiempo considerable hasta tener noticia de cualquier suceso del que no fuéramos testigos directos, de tal manera que su representación lingüística conservaba siempre su esencial lejanía. ${ }^{21}$ No obstante, las telecomunicaciones

Asistimos, en efecto, a una inversión del posicionamiento de Kant, que supedita la comprensión de los fenómenos a su explicación mediante las leyes establecidas por los juicios que articulan los conceptos (categorías) de la facultad intelectual del entendimiento.

19 L. Sáez, Movimientos filosóficos actuales. Madrid: Trotta, 2009, p. 192.

20 M. Heidegger, El Ser y el Tiempo, Op. cit., p. 120.

21 La expresión «representación lingüística» equivale, en este contexto, al concepto de «aura», definido como la «manifestación irrepetible de una lejanía (por cercana que pueda estar)». W. Benjamin, «La obra de arte en la época de su reproductibilidad técnica», en Discursos interrumpidos I, tr. J. Aguirre. Madrid: Taurus, 1990, p. 24. Sin duda, la percepción de 
de la era conectiva logran, a diferencia del tráfico indolente de la época de la navegación, transmitir información acerca de cualquier lugar del mundo de manera inmediata, con lo cual aquella latencia se reduce o simplemente desaparece, mientras que nuestro presente existencial se amplía hasta espacios inaccesibles ónticamente. ${ }^{22}$

En este contexto, la Tierra se satura y encoge en un cuasi-nada o, si se prefiere, un todo simultáneo y homogéneo, mientras que lo gigantesco amenaza, bajo una diversidad de máscaras sin precedentes, con hacerse cada vez más pequeño o (en términos actuales) miniaturizarse: «Lo que sucede en el rincón más apartado puede percibirse simultáneamente aquí en tiempo real. El aquí se convierte en otra parte cualquiera y, al final, termina siendo un 'por todas partes'. [...] Hoy todo se convierte en cercanía, por lejano que esté». ${ }^{23}$ Efectivamente, los medios ultra-rápidos actuales reducen o, simplemente, neutralizan la latencia característica de la época de la navegación, ${ }^{24}$ en lo que constituye una corriente de «integración mundial» que supone, aparentemente, un incremento vertiginoso de la velocidad cuyo significado podemos descifrar sin demasiado esfuerzo como «aceleración física», dando lugar a una aldea global cada vez más pequeña donde todos vivimos aglomerados, como ha estudiado detenidamente el teórico de la comunicación canadiense McLuhan.

Ahora bien, lo más cercano (Distanz) en un sistema de coordenadas cartesiano no tiene por qué ser, en absoluto, lo que se halla menos lejos (Ferne) de

la comparecencia de los dioses griegos en la cercanía del futbolista F. Beckenbauer, por parte de Heidegger, cuando seguía frente a la pantalla de televisión, con ocasión del campeonato del mundo de fútbol (Múnich, 1972), los partidos de la selección alemana, ilustra a la perfección dicha figura de pensamiento. $C f$. F. Kittler, «El des-alejar», en G. Aranzueque (ed.), Ontología de la distancia: filosofías de la comunicación en la era telemática. Madrid: Abada, 2010, pp. 116-17.

22 La capacidad de contemplar eventos acaecidos más allá de nuestra presencia física aumenta la complejidad de nuestra experiencia del presente y, por ende, del pasado (olvidamos más, en tanto que el volumen de acontecimientos a recordar ha crecido exponencialmente) y del futuro. En esta medida, genera incertidumbre y, por lo tanto, miedo. $C f$. V. Sanfélix Vidarte, «Terror y globalización», en R. Ávila, E. Ruiz y J. M. Castillo (eds.), Miradas a los otros. Dioses, culturas y civilizaciones. Madrid: Arena Libros, 2011, pp. 226-28.

23 R. Safranski, ¿Cuánta globalización podemos soportar?, tr. R. Gabás. Barcelona: Tusquets, 2004, pp. 85-86.

24 Algunas investigaciones científicas corroboran esta idea de manera contundente y, cuanto menos, curiosa. El sociólogo S. Morgan, de la Universidad de Harvard, realizó en 1967 un experimento en el cual envió cartas a diversas personas pidiéndoles que las reenviaran a sus amigos, que a su vez las enviarían a sus amigos para acabar dirigiendo la carta a cierta persona que vivía en Boston; de este modo, descubrió que la mayoría de cartas que hicieron todo el recorrido lo consiguieron en una media de cinco o seis relaciones. Por su parte, el físico L. Barabasi, de la Universidad de Indiana, pondera que la mayoría de páginas webs se pueden relacionar por medio de unos 18 o 19 clics de media. 
nosotros. De hecho, la anulación universal de lo que los romanos denominaron «distancia» en un sentido puramente físico-geométrico (resoluble técnicamente) supone una cercanía engañosa, porque entrelaza lo lejano con lo cercano de un modo difícil de desenmarañar, en un horizonte de percepción ampliado artificialmente en función del cual reduce, heideggerianamente hablando, el acontecimiento del ser en su estado naciente (indisponible por antonomasia, como decreta la dimensión encubridora del ser) a lo que está ahí «ante-los-ojos» o a la «disposición» del arbitrio humano.

En esta medida, la dinámica de la «des-espacialización» del globo o el «des-alejamiento» del alejamiento acarrea inexorablemente el oscurecimiento del mundo, en tanto que desahucia la singularidad, el carácter único e irrepetible o, mejor dicho, el «aura» de la cosa misma hasta tal punto que, como señala Kittler, «los lejanos planetas, por decirlo con Ser y tiempo, están más cercanos a nuestros ojos o más salidos de lo oculto que los circuitos encima de nuestro escritorio y en el interior de nuestros bolsillos»». ${ }^{25}$

Con todo, los ecos heideggerianos no se agotan aquí. Y es que, en contraste con la actitud respetuosa de la técnica originaria, los medios masivos desafían a la physis con el objeto de construir técnicamente el acontecimiento del ser, tal y como atestigua el simulacro a placer y sin ningún esfuerzo, a cargo de la $\mathrm{CNN}^{26}$, del acontecimiento de la guerra del Golfo en toda su cotidianidad como un «teatro», habilitado por un amplio abanico de cámaras fotográficas y dispositivos de video acomodados estratégicamente en los distintos ángulos de la contienda, junto al ritmo vertiginoso que marcan las oportunas narraciones acerca de los detalles del enfrentamiento (las arengas, los bombardeos, etc.) por parte de los corresponsales, así como el abrumador arsenal de recursos semióticos, semánticos y pragmáticos listos para incrementar subrepticiamente la influencia seductiva ${ }^{27}$ de las imágenes y palabras implicadas (aparentemente caóticas, pero consistentes ${ }^{28}$ ), si bien es cierto que el progreso tecnológico ha

25 F. Kittler, Loc. cit., p. 112.

26 Este evento televisivo constituye un punto de inflexión en lo que se refiere a las técnicas o tácticas informativas. Mientras que tanto las dos guerras mundiales como la guerra civil española se recuerdan como las guerras de la radio, la guerra del Golfo permanece en la memoria colectiva como la primera guerra televisada en directo, por lo cual la televisión se convierte en la principal fuente de información, en detrimento de la radio.

27 Da que pensar que la etimología de «seducción» provenga del latín se-ducere, que significa separar del «buen camino», «desviar del bien» o «empujar al error».

28 Los llamados «principios de la propaganda» de Goebbels, ministro de la Alemania nacionalsocialista, continúan siendo un referente inexcusable al respecto. No obstante, cabe destacar el recurso de la manipulación, eficacísimo a la hora de fomentar la hiperfobia, entendida como cierto desajuste entre el miedo experimentado hacia ciertos fenómenos y su peligrosidad objetiva. $C f$. R. Barthes, Lo obvio y lo obtuso. Imágenes, gestos, voces, tr. C. Fernández. Barcelona: 
concedido ciertos soportes autónomos a la imagen, en virtud de los cuales aventaja a la escritura desde un punto de vista persuasivo.

Se trata, no obstante, de una «provocación» en el sentido heideggeriano del término, en tanto que fuerza a la physis a que aprovisione imágenes morbosas y responde a un plan establecido, a saber, captar la mayor cantidad posible del recurso escaso que representa la atención de la audiencia, en un marco competitivo donde el canibalismo empresarial, las fusiones-adquisiciones, las participaciones cruzadas, el sensacionalismo, ${ }^{29}$ y un largo etcétera de estrategias adaptativas están a la orden del día con tal de llegar a todos, en todas partes y en todo momento, ${ }^{30}$ en lo que constituye una omnidifusión de la realidad a domicilio que organiza nuestras vidas al modo de un «sistema postal», según el modelo general de la cibernética de Wiener.

El hombre, en esta medida, interioriza la esencia de la técnica y la corresponde incluso cuando reniega de ella, de forma que habita ya la dimensión de la provocación como la materia prima más importante, se halla arrojado en su espesura pro-ducido técnicamente para comprender compulsivamente todo lo existente como «existencias», en detrimento de la actitud de escucha que procura el advenimiento del ser en su verdad; visto así, el desarraigo del hombre no responde a decisionismo alguno sino a su condición radicalmente abierta, en virtud de la cual constituye el escenario donde el mundo (vale decir, la técnica moderna en su acepción ontológica o el «Ge-stell») tiene su entrada y aparece como tal.

Pues bien, dirigida y asegurada en estos términos, la ficción representativa de la guerra consagra el dominio universal de la eficiencia y sus procedimientos cosificantes preestablecidos. Huelga decir que la guerra convertida en «espectáculo» (la muerte en la imagen) posee numerosas expectativas de éxito, en la medida en que alberga dosis de acción y suspense propias de un filme del maestro Hitchcock, aderezadas con efectos especiales por cortesía de los militares.

Paidós, 2000, pp. 29-47. Valga como ejemplo los patos embadurnados a propósito en petróleo, con la pretensión de cambiar la percepción que los occidentales tenían de la guerra del Golfo.

29 Dado que la popularidad de un tema escándalo supone el éxito del medio que lo saca a la luz, el resto de medios buscan copiar, bajo cualquier circunstancia, las «propuestas de excitación» que gozan del favor de la audiencia, «hasta llegar el punto en el que una sociedad completamente monotemática aparece sincronizada al compás de una misma y única excitación». P. Sloterdijk, y H. J. Heinrichs, El sol y la muerte. Investigaciones dialógicas, tr. G. Cano. Madrid: Siruela, 2004, p. 79.

30 Podría decirse, desde esta perspectiva, que la técnica moderna hereda el trono vacío del Dios judeo-cristiano, en tanto que realiza el atributo teológico de la ubicuidad: como Dios, satura lo real con su presencia, invisible pero omnipotente. 
A decir verdad, la nueva configuración del espacio-tiempo no sólo ha trasfigurado paulatinamente nuestra cultura material ${ }^{31}$ sino también nuestra manera de pensar y de valorar, ${ }^{32}$ de modo que responde más a una cuestión de fines que de medios. ${ }^{33}$ Es más, ha modificado radicalmente el modo en que conceptuamos la realidad de manera tal que la confundimos con el mismo medio, en tanto es efecto suyo: «No vemos [...] la realidad [...] como es, sino como son nuestros lenguajes. Y nuestros lenguajes son nuestros medios de comunicación. Nuestros medios de comunicación son nuestras metáforas, nuestras metáforas crean el contenido de nuestra cultura». ${ }^{34}$ Desde esta óptica, confundimos la riqueza viva o tener-lugar del acontecimiento de la guerra del Golfo con la construcción operativa, artificiosa y espuria de su desarrollo, seguido en vivo y en directo, sin dilación ni efecto diferido, por millones de espectadores en sus confortables hogares desde el mismísimo día de su explosión, como si de un espectáculo deportivo, el cotilleo o un spot publicitario se tratase; y es que, como observa Sartori, «con la televisión, la autoridad es la visión en sí misma, es la autoridad de la imagen. [...] El ojo cree en lo que ve; $\mathrm{y}$, por tanto, la autoridad cognitiva en la que más se cree es lo que se ve. Lo que se ve parece 'real', lo que implica que parece verdadero»». ${ }^{35}$

Sin embargo, la verdad es que no hay apropiación del acontecimiento en cuestión, pues una cosa es tener noticia de algo y otra muy distinta reconocer ese

31 El nuevo contexto comunicativo global, mucho más fluido y dinámico, requiere un giro del sistema económico hasta un modelo reticular: «Las experiencias de la Unión Soviética [...] indican que si bien las economías altamente centralizadas se bastan para alcanzar el nivel de industrialización presente en la Europa de la década de 1950, resultan espantosamente inadecuadas para crear las que se han llamado economías complejas 'postindustriales', en las cuales la información y la innovación tecnológica tienen un papel mucho más amplio». F. Fukuyama, El fin de la historia y el último hombre, tr. P. Elías. Barcelona: Planeta, 1992, pp. 16-17.

32 W. Lippmann ha demostrado que los medios informativos son la fuente primaria de las ficciones que se hallan a la base de la opinión pública, en tanto que determinan nuestros mapas cognitivos del mundo que queda más allá del entorno inmediato. $C f$. J. M. Rubio Ferreres, «Filosofía y medios de comunicación. Más allá de la información», en R. Ávila, J. A. Estrada y E. Ruiz (eds.), Itinerarios del nihilismo. La nada como horizonte. Madrid: Arena Libros, 2009, pp. 309-10.

33 El poder mediático ha generado en la literatura filosófica un discurso hipercrítico contra los medios, desde la crítica de Nietzsche al periodismo por participar de la mediocridad del hombre rebaño hasta la denuncia de Sartori a la televisión porque empobrece el sistema cognitivo del homo sapiens, pasando por el ataque de la Escuela de Frankfurt a los medios de comunicación de masas en tanto que reducen la cultura a meros «productos de consumo». Cf. Íbid., pp. 306-07.

34 Postman, N., Amusing Ourselves to Death: Public Discourse in the Age of Show Business. Nueva York: Penguin Books, 1985, p. 15 (la traducción es nuestra).

35 G. Sartori, Homo videns. La sociedad teledirigida, tr. A. Díaz. Madrid: Taurus, 1998, p. 72 . 
algo en tanto que algo. Ciertamente, el modo psicosocial de percibir el espaciotiempo bajo el signo del universo video-electrónico ignora por completo, más allá de las viejas caracterizaciones que vertebraban el imaginario social de la época de la imagen del mundo, la «diferencia óntico-ontológica» heideggeriana entre la dimensión vertical del acontecimiento de venir a presencia un mundo de sentido (la experiencia de la muerte in fieri), tan sólo experimentable desde la perspectiva «ser-a-la-mano» (Zuhandensein), y la dimensión horizontal del mundo de sentido ya presente (Anwesen) y representable (el aspecto de los cadáveres) en una superficie homogénea de píxeles desde el enfoque «ser-antelos-ojos» (Vorhandensein).

En tal disposición de los términos, podemos concluir que el afán desalejante de los medios audiovisuales realiza el «máximo olvido del ser», en la medida en que la co-instantaneidad entre acontecimiento y noticia forma parte de la función interna de la provocación, a modo de mecanismo del sistema operatorio en virtud del cual la técnica moderna expande su poder omnímodo en el «mundo de la vida» (Lebenswelt) como perfeccionamiento ilimitado de sí, ${ }^{36}$ condensando y registrando todos los tiempos (más allá de toda crítica).

En definitiva, el ser continúa impensado, mientras que la lejanía, como ya hiciera el desierto de Nietzsche, ha crecido, pues por muy ajustados y nítidos que nos parezcan, los estimulantes simulacros videoelectrónicos llamados a re-crear la articulación interna de la physis con tal de complementar nuestra fragmentada apercepción de la misma reifican su insospechada figura (constitutivamente metamórfica) para hacerla controlable y normalizable, la desterritorializan, la domestican, la enervan y la desangran, por lo que está condenada a diseminarse, para deleite del «último hombre», en el devenir comercial del espacio telemático.

Pero más allá de la cosificación humana que supone, se trata, no obstante, de una empresa esencialmente imposible, ya que la voluntad de dominio de la técnica moderna deja fuera (Auslassen), toda vez capturada la distancia, lo que hace falta para el des-velamiento de la verdad ontológica, a saber, el acontecimiento del permanecer fuera (Ausbleiben ${ }^{37}$ ) o, dicho de otro modo, «lo que retiene, lo que el ser no envía en cada envío, sino que se lo reserva en lo oculto,

36 Heidegger denomina «usura» al funcionamiento tecnológico como tal, sin dirigirse a ninguna meta externa: «El consumo del ente, como tal y en su decurso, está determinado por el equipamiento en el sentido metafísico, algo por medio de lo cual el hombre se hace 'señor' de lo 'elemental'. El consumo incluye el uso reglado del ente, que se convierte en oportunidad y materia para realizaciones y para la intensificación de éstas. Este uso se utiliza en beneficio del equipamiento. Pero en la medida en que éste va a parar a la incondicionalidad de la intensificación y del aseguramiento de sí y tiene realmente como meta la ausencia de metas, este uso es usura». M. Heidegger, «La superación de la metafísica», en Conferencias y artículos, op. cit., p. 67.

$37 C f$. M. Heidegger, Nietzsche II, tr. J. L. Vermal. Barcelona: Destino, 2000, p. 293. 
permanece como algo olvidado, impenetrable e inaccesible». ${ }^{38}$ Asistimos, por lo tanto, al olvido del olvido, es decir, el olvido del retraimiento u ocultación que acompaña, en tanto que pertenece a la esencia del advenimiento, a toda donación de sentido.

En este contexto, lo extraño ha dejado, paradójicamente, de extrañarnos, ${ }^{39}$ y sus antaño fascinantes zonas de sombra se exfolian en una inquietante atmósfera marcada por la banalidad y la indiferencia, ${ }^{40}$ donde se gestan graves dilemas morales imprevistos por Heidegger. ${ }^{41}$

En primer lugar, cabe destacar el fenómeno de la «ética a distancia en la época del mando a distancia televisivo». El desarrollo de los conflictos bélicos acaecidos, entre los años 1991 y 2001, en el territorio de la antigua Yugoslavia, pone de manifiesto que lo lejano se acerca moralmente aunque la acción se produce desde una gran distancia, en lo que constituye una nueva estructura de violencia que exige novedosas formas de seguridad, con costes en términos de libertades personales.

Consternada por las imágenes visionadas in distans, Occidente sintió la obligación moral de pasar a la acción llevando a cabo bombardeos cerca del lugar pero desde una gran altura, evitando a toda costa tener contacto con los mundos complejos de la vida para mantenerse a salvo sin correr riesgo alguno: «Una guerra en la que apenas se toca el suelo corresponde realmente al compromiso moral del sillón ante el televisor, ${ }^{42}$ donde no hay ningún contacto con el suelo y el auxilio sin riesgos puede desplegar imaginariamente sus energías vitales. Las guerras según condiciones televisivas son un producto paralelo al nuevo tipo del conductor mediático, rodeado de mandos y botones». ${ }^{43}$ Ahora bien, la altitud alcanzada por los bombarderos fue en detrimento de su precisión,

38 D. Sánchez, loc. cit., p. 172.

39 «Importamos lo extraño y lo normalizamos en lo propio, de forma que [...] lo otro ha sido domesticado [...] procurándole una cercanía pulcra, desinfectada, en la que no ha sido capturado lo que de verdad podría extrañarnos». L. Sáez, Ser errático..., Op. cit. p. 68.

40 «Junto a la noticia de la matanza o de la hambruna, la tremenda caída de un equipo de fútbol. Junto al hundimiento de la barcaza que conduce a unos desarrapados, el hundimiento de los valores bursátiles». L. Sáez, «Ficcionalización del mundo...», Loc. cit. pp. 64-65.

$41 C f$. R. Safranski, Op. cit. pp. 82-85.

42 El fenómeno de la «migración» pone de relieve la hipocresía que enmascara semejante compromiso: «Cuando la miseria del otro rompe esa lejanía, cuando se hace presente en nuestra sociedad a través de los incontenibles fenómenos migratorios, la solidaridad muta en xenofobia y los ideales democráticos se transforman en rasgos identitarios listos para facilitar la exclusión». O. Barroso Fernández, «Patologías del criterio en la era de la globalización», en L. Sáez, P. Pérez e I. Hoyos (eds.), Occidente enfermo. Filosofia y Patologías de Civilización. Múnich: Grin, 2011,p. 112.

43 Safranski, R., Op. cit. pp. 82-83. 
con lo cual se produjeron numerosos daños colaterales como la destrucción de instalaciones no militares e, incluso, la muerte de civiles inocentes. ${ }^{44}$

En efecto, la actitud miedosa de Occidente, traducida en un despliegue de medios militares desproporcionado, nos enseña que el remedio puede ser peor que la enfermedad, tal y como sugiere, por su parte, $\mathrm{T}$. Todorov cuando señala que «el miedo a los bárbaros es lo que amenaza con convertirnos en bárbaros». ${ }^{45}$

En segundo lugar, merece la pena detenerse en la «complicidad involuntaria entre el terror y los medios». Como observa Sloterdijk, los ciudadanos de las urbes occidentales esperan siempre, sumidos en el aburrimiento y rodeados de medidas de seguridad física, noticias del exterior, hasta el punto de que sus metabolismos necesitan sentir-se-amenazados histéricamente, ${ }^{46}$ desde este prisma, V. Sanfélix denuncia que «el miedo parece tener una tendencia interna al crecimiento. Una vez puesto en marcha, crece como una bola de nieve deslizándose por la pendiente de unos medios de comunicación que con sus múltiples ecos lo agrandan de modo sistemático». ${ }^{47} \mathrm{Y}$ es que, a sabiendas de la histeria generalizada, los mass media alimentan cierta hiperfobia en las metrópolis del mundo globalizado, con el propósito de conseguir el mayor número de adeptos posible: «Lo vemos casi a diario. Periódicamente se desatan alarmas que luego quedan en bien poco. La gripe A probablemente haya sido el último episodio de estas alarmas, [...] pero antes fue la gripe aviar, y antes las vacas locas, y antes el colapso informático que se preveía para el cambio de siglo, y antes... [...] De este efecto estereofóbico [...] se sirve el terrorismo global para agigantar su imagen». ${ }^{48}$

Efectivamente, el circo mediático depende del aprovisionamiento de acontecimientos para mantener el clima de miedo preponderante, y los terroristas ofrecen los acontecimientos más solicitados al respecto, puesto que el ataque se vende siempre, y cuanto más brutalmente se produce, más gratificante

44 El mayor número de fuentes coincide a la hora de estimar que de las 130.800 personas muertas o desaparecidas en la guerra, aproximadamente 58.000 fueron combatientes, 55.800 civiles y 17.000 indeterminados.

45 T. Todorov, El miedo a los bárbaros. Más allá del choque de civilizaciones, tr. N. Sobrequés. Barcelona: Galaxia Gutenberg/Círculo de Lectores, 2008, p. 18. Por los demás, esta política conduce a un doble fracaso. Cf. Ibid., p. 19.

46 Según la psicopatología de la sociedad concebida por Sloterdijk, la disponibilidad a la catástrofe denominada «complejo catastrófico» constituye uno de los síntomas más acuciantes de la sociedad exhausta y esquizoide del siglo XX, entendido como: «Una perturbación colectiva de la vitalidad a través de la cual las energías de lo vivo se desplazan hacia la simpatía con lo catastrófico, lo apocalíptico, lo espectacular y lo violento». P. Sloterdijk, Crítica de la razón cínica (vol. 1), tr. M. A. Vera. Madrid: Taurus, 1989, p. 171.

47 V. Sanfélix, loc. cit., p. 224.

48 Ibid., p. 223. 
resulta la recompensa mediática. Por su parte, los terroristas han entendido a la perfección que la estructura hipercomunicativa del escenario mediático favorece su expansión unilateral, de tal manera que siembran el terror a fin de que los medios de comunicación lo difundan globalmente; es más, «la esencia del terrorismo moderno implica el uso del aparato de los medios en su forma específica de difundir los mensajes». ${ }^{49}$ Por ejemplo, en el caso de los atentados del $11-S$, parece evidente que los terroristas planificaron sus operaciones como un «acontecimiento mediático», ya que establecieron un intervalo de veinte minutos entre el primer y el segundo impacto contra las torres gemelas del World Trade Center; en efecto, aproximadamente 1.500 millones de personas vieron en directo el impacto del segundo avión contra la segunda torre porque ya habían sido avisados cuando el primer avión chocó contra la primera torre.

Vistas así las cosas, el fenómeno de la «complicidad involuntaria entre el terror y los medios» añade el sentimiento de la propia amenaza con respecto al de la «ética a distancia en la época del mando a distancia televisivo», además de plantear un dilema moral entre el deber (alentado por intereses espurios ${ }^{50}$ ) de informar, de un lado, e implementar la posibilidad de no informar para impedir que el terror se difunda, de otro.

Borja García Ferrer es Doctor en Filosofía. Ocupa un puesto en el Departamento de Filosofía II en la Universidad de Granada.

Linea de investigación

Filosofía contemporánea, ontología política, crítica de patologías.

Publicaciones recientes

«Tiempos de penuria: el 'bombardeo semiótico' o la conquista del espacio interior». Otros logos. Revista de Estudios Críticos, 4 (2013), pp. 39-63 [ISSN 1853-4457]

«El cuerpo y sus expresiones patológicas en el devenir contemporáneo de la infoesfera», Éndoxa: Series Filosóficas (en prensa) [ISSN 2174-5676]

«Del obrero alienado al 'ser-en-el-zombi'. Sobre el nuevo malestar del homo laborans en el Capitalismo post-industrial», Astrolabio. Revista Internacional de Filosofía (en prensa) [ISSN 1699-7549].

Dirección electrónica: borja_co@hotmail.com

49 R. Safranski, Op. cit., p. 85.

$50 \mathrm{El}$ incremento de la venta de automóviles todoterreno y de urbanizaciones blindadas de seguridad, por una parte, y la negativa de algunos ayuntamientos a la hora de empadronar a los emigrantes, por otra, atestiguan, respectivamente, la rentabilidad comercial y política de la hiperfobia. Cf. Z. Bauman, Tiempos líquidos. Vivir en una época de incertidumbre, tr. C. Corral. Tusquets: Barcelona, 2007, pp. 22-23. 
